\title{
Meso-American Nephropathy in El Salvador: Increasing Farmer Participation in MeN Prevention Efforts
}

\author{
Keven Bermudez $^{1}{ }^{\circledR}$, Carlos Orantes ${ }^{2}$, Montserrat León1, Marta Jiménez¹, Nicole Vidal1, \\ Pol De Vos ${ }^{1}$ \\ ${ }^{1}$ Institute for Global Health and Development, Queen Margaret University, Edinburgh, UK \\ ${ }^{2}$ National Health Institute, Ministry of Health (MINSAL) of San Salvador, San Salvador, El Salvador \\ Email: kevbermudez@yahoo.es
}

How to cite this paper: Bermudez, K., Orantes, C., León, M., Jiménez, M., Vidal, N. and De Vos, P. (2019) Meso-American Nephropathy in El Salvador: Increasing Farmer Participation in MeN Prevention Efforts. Occupational Diseases and Environmental Medicine, 7, 50-63.

https://doi.org/10.4236/odem.2019.72005

Received: April 28, 2019

Accepted: May 24, 2019

Published: May 27, 2019

Copyright $\odot 2019$ by author(s) and Scientific Research Publishing Inc. This work is licensed under the Creative Commons Attribution International License (CC BY 4.0).

http://creativecommons.org/licenses/by/4.0/

(c) (i) Open Access

\begin{abstract}
Objectives: This paper highlights and discusses major factors affecting Salvadoran farmers' involvement in National Health System-led efforts to prevent $\mathrm{MeN}$ in El Salvador and includes some recommendations to enhance their involvement. Methods: The study, conducted in El Salvador in June 2018, involved 10 life-long farmers residing in five $\mathrm{MeN}$-affected communities in Chalatenango and Usulutan Departments who were either MeN-free or MeN-controlled, to understand through semi-structured, qualitative interviews their experience of participation in broader epidemic control efforts. Complementary interviews held with two nephrology teams and a senior representative of the grassroots-level National Health Forum operating in the same area, provided necessary contrast. Interview questions were informed by reference to the Adaptation and Development after Persecution and Trauma (ADAPT) model [1] as applicable in post-conflict environments like El Salvador to analyze contextual factors influencing community participation. Findings: Farmers are scarcely involved in wider $\mathrm{MeN}$ prevention efforts in El Salvador despite greater National Health System emphasis on encouraging community participation since the approval of the 2009 Health Reform [2]. This study found that widespread insecurity due to gang warfare, declining family and social networks due to high murder rates and international migration, and unresolved sense of injustice over unremitting poverty are among major factors with potential destructive effect on farmer participation. Conclusions: Health system-led MeN prevention responses need to encompass attention to persisting social vulnerabilities in economically and socially marginalized communities in order to enhance farmer participation in this effort. This paper concludes with some recommendations on how this can be done.
\end{abstract}




\section{Keywords}

El Salvador, Meso-American Nephropathy, CKDu, Pesticides, Dehydration, Heat Stress, Farmer Resilience

\section{Introduction}

Since 2002, different sources of health information in El Salvador have been calling attention to the high rate of deaths in rural communities by a variant of Chronic Kidney Disease (CKD) in which traditional causes, such as the presence of comorbidities like diabetes mellitus and hypertension, are not necessarily part of the clinical picture [3] [4] [5] [6]. Although its principal victims are individual small farm agricultural workers, a growing number of women and minors with no history of direct involvement in agricultural activities are equally affected by this epidemic [7]. Similar disease manifestations have developed in agricultural areas belonging to other Central American countries, from Mexico to Panama [8]. Its widespread in the region has led to the epidemic being referred to as Mesoamerican Nephropathy (MeN) or Chronic Interstitial Nephritis of Agricultural Communities (CINAC) in regional scientific circles. Some South American countries, as well as countries like Sri Lanka, India, and Egypt have registered an epidemic with similar features [9], where the disease is known as Chronic Kidney Disease of Unknown Etiology (CKDu).

Recent epidemiologic reports published by the Ministry of Health of El Salvador (MINSAL) do not reflect the specific mortality rate due to $\mathrm{MeN}$, but, rather, the sum total of hospital deaths caused by CKD based on the combined total of different CKD-related diagnoses, including MeN. During the period 2006-2017, the MINSAL reported 8198 hospital deaths related to CKD [10]. Although death rates for other single diagnoses are higher than those associated with $\mathrm{CKD}$, the combined total of deaths due to CKD-related diagnoses makes CKD the leading cause of mortality among adults in the country. The MINSAL registers between 500 and 700 new cases of kidney failure annually [11]. Given this high rate, and taking into consideration that, as Dr. Garcia-Trabanino points out the published statistic does not reflect the full reality regarding deaths by $\mathrm{MeN}$, in that most of those affected die in the anonymity of their own homes [10], the concerned Ministry as well as its partners in the Pan American Health Organization (PAHO) has declared the MeN epidemic as a still unresolved public health emergency [12].

The exact causes of $\mathrm{MeN}$ are being investigated from different angles. Since the disease has struck agricultural workers in particular, research efforts have mainly focused on clarifying common occupational risk factors. Two major hypotheses have emerged from different studies, which may even be interlinked: On one hand, studies have found that chronic and largely unprotected exposure to synthetic pesticides in the course of their work, particularly to organochlo- 
rides and organophosphates [13], is a common experience among $\mathrm{MeN}$-affected farmers in all concerned countries. Clinical tests have shown structural damage in $\mathrm{MeN}$-affected patients' kidneys caused by toxic residue build-up, as the kidneys are unable to filter and eliminate it, according to their main function [3]. Another line of research has been concerned with chronic dehydration as another common experience among $\mathrm{MeN}$ patients caused by poor rehydration practices in the course of strenuous physical work in the year-round hot and humid climactic conditions that characterize Pacific ocean coastal areas, where $\mathrm{MeN}$ is prominent [14]. It is known that chronic dehydration can negatively affect kidney function [15].

Alongside these major hypotheses [16], the context of poverty in which farmers evolve also plays a role in the development of $\mathrm{MeN}$ in El Salvador. In an impoverished state, small farmers cannot adequately prevent occupational risk factors. They are driven to use cheap synthetic pesticides as they are able to maximize their crop yield at a minimal cost. Many, who work in farmer cooperatives for limited periods tend to overwork, as their income depends on volume of daily production, which causes them to neglect rehydration pauses, if they are even allowed to take them by their crew captains. Their regular diet is poor in essential nutrients. Use of unprescribed analgesics and alcohol abuse to kill pain from strenuous physical labor is widespread within this population group [3]. With limited financial resources, many do not invest in necessary protective equipment while exposed to highly toxic pesticides. They neither use health services on a regular basis. All these factors combined can weaken the body's immunological system and, therefore, overexpose them to health risks in their surrounding environment.

In actuality, and as reflected in the Declaration of San Salvador [12], MeN has, most likely, a multifactorial origin. Reference [17] states that heat stress and pesticide exposure can have a synergistic effect, as heat stress during a period of physical exertion may increase workers' exposure to environmental pollutants, by "forcing greater pulmonary ventilation leading to greater inhaled intake, as well as of increased doses absorbed through the skin due to dilatation of skin's capillaries and pores". Nevertheless, research studies continue to focus on determining which of the two major identified factors (pesticide exposure, dehydration caused by heat stress) is the primary trigger [18]. A counterproductive effect of this approach is that as long as the "culprit" hasn't been identified with absolute scientific certainty, little is being done to curtail each of the identified contributing factors. Here is where the National Health System and its partner the National Health Forum can play a vital role to enhance prevention by involving at-risk farmers in MeN prevention initiatives.

This qualitative research examines the existing link between farmers in two $\mathrm{MeN}$ hotspots in El Salvador and state-led MeN prevention initiatives. El Salvador went through a 12-year civil war that ended in 1992, which was primarily fought in rural areas, killing at least 75,000 people [19] and causing high rates of displacement. Once previously exiled peasants resettled back in country follow- 
ing the peace accords, many continued to face a post-conflict environment plagued with widely acknowledged adversities, including pervasive insecurity due to gang violence, family breakdown due to high murder rates and mass out-migration, persistent poverty due to unemployment, and disease outbreaks, such as typhoid fever, dengue, zika virus infection and MeN. It was, therefore, necessary to apply a conceptual framework that would allow exploration of contextual factors influencing farmers' social engagement. The Adaptation and Development after Persecution and Trauma (ADAPT) model [1] provides a suitable theoretical framework to understand the potential impact of high-scale challenges such as these on community participation, as well as to identify available community resources to enhance community participation.

The ADAPT model defines five core psychosocial pillars that characterize stable societies. These are:

1) Safety/security

2) Bonds/Networks

3) Justice

4) Roles and Identities

5) Existential meaning

These pillars can be understood as adaptive systems that enable adaptive responses. Widespread damage to these pillars, as occurs in the context of mass conflict, creates general instability, which may lead to maladaptive responses, such as social disengagement, unless they are appropriately repaired. Pillar-stabilization depends on local capacity to mobilize available intra-personal and interpersonal resources. However, war-torn and impoverished societies may lack substantial resources to restore functioning systems promptly enough. As well noted in the extensive available bibliography on global humanitarian crisis, available infrastructure has been destroyed and several dangers persist in the environment that local authorities are generally slow at rebuilding or removing. Qualified human resources are scarcely available as many have either died, migrated, become ill, injured or handicapped. Distrust from years of violent confrontation may prevent cooperation among different social groups and, instead, entrench existing social fractures. People caught in extremely precarious life situations may be far more concerned with their own survival than in participating in community reconstruction efforts. This post-conflict environment may become a breeding ground for a still wider range of adversities that keep people locked in fear well after the cessation of hostilities.

This research first analyzes the state of three fundamental pillars in MeN-affected farming communities in El Salvador for their potential impact on farmer participation in collective MeN prevention efforts: Safety/security, Bonds/Networks, and Justice. It will then discuss efforts undertaken by the Ministry of Health in El Salvador, through the Integrated and Integral Health Networks and in partnership with the grassroots-level National Health Forum (NHF), founded in 2010 as part of the FMLN government's health system reform, to involve community members for health prevention purposes. Results obtained from this 
analysis clarify the need to reinforce this partnership by enhancing its capacity to leverage pillar repair, so as to encourage the highest level of farmer participation in the design of prevention strategies to respond to the MeN health threat. This article concludes with a set of recommendations as to how this partnership can possibly implement this type of support.

\section{Methods}

\subsection{Study Design}

Since previous research on MeN prevention in El Salvador is scarce, this study adopted a qualitative approach to explore the topic under study. Through this approach, it was possible to engage different stakeholders in their natural setting to collect their experience-based insights concerning $\mathrm{MeN}$ prevention and also create a foundation for further research.

\subsection{Interviews}

To explore the personal experiences of participants in this specific domain, the study developed a semi-structured, individual interview guide containing open-ended questions, in simple language, as useful to uncover as much rich descriptive data as possible. Interview questions were developed following a desk review of relevant literature on $\mathrm{MeN}$ in El Salvador, and with particular reference to the Adaptation and Development after Persecution and Trauma (ADAPT) model [1], which provides a useful lens to analyze contextual factors that might disrupt community participation in post-conflict environments like El Salvador.

\subsection{Study Area \& Sampling}

Chalatenango and Usulután departments were selected as study sites as they offered the opportunity to examine this research question in relation to at least two departments where MeN has been prominent since it was first detected in 2002. Since they are located at diametrically opposite country extremes, they also offered necessary contrast. Within each of these departments, and through referrals made by Ministry of Health representatives based in the capital San Salvador, the study first contacted medical teams based in the nephrology unit of La Palma (Chalatenango) and Ciudad Romero (Usulután) health centers who have been on the frontline of the response to the MeN epidemic. National Health Forum leaders based in San Salvador also facilitated contact with a senior representative of this popular health movement based at its branch office at Radio Mangle in Ciudad Romero. After conducting interviews with nephrologists and health promoters based in these centers, the study sought to include the broadest sampling of farmers in the surrounding communities who met the following inclusion criteria:

The farmer sampling criteria, as detailed in Table 1, provided the opportunity to explore whether certain farmers' currently stable health status derived from their link with state-led MeN prevention efforts, or whether it derived instead 
Table 1. Inclusion \& Exclusion Criteria.

\begin{tabular}{|c|c|}
\hline Inclusion criteria & Exclusion criteria \\
\hline $\begin{array}{l}\text { Male farmer residing in area of high } \\
\text { concentration of MeN cases for at least } 20 \text { years. } \\
\text { 30+ years regular work in agriculture in similar } \\
\text { conditions as farmers who have suffered MeN. } \\
\text { Absence of MeN diagnosis or MeN-controlled/in } \\
\text { remission living in the community. } \\
\text { Willingness to participate in research. } \\
\text { Able to provide informed consent. }\end{array}$ & $\begin{array}{l}\text { Male farmer residing in area of low } \\
\text { concentration of MeN cases. } \\
\text { occasional basis, with limited exposure to } \\
\text { MeN-related risks. } \\
\text { Hospital-based, MeN-affected farmer or } \\
\text { farmer not being medically monitored. } \\
\text { Declines participation in research. } \\
\text { - Unable to provide informed consent. }\end{array}$ \\
\hline
\end{tabular}

from successful protective measures to ward off $\mathrm{MeN}$-related risks they had developed in isolation. In the latter case, it would be possible to explore whether they had been able to share their acquired knowledge on "homegrown" prevention strategies with the wider public through participation in state-led prevention efforts. Interviewed nephrologists and health promoters referred the researcher to a total of 10 farmers in the surrounding communities who met the study's inclusion criteria. The total number of farmers receiving direct support from the National Health System and its partner the National Health Forum in these areas is 300 .

Both the National Health Ethics Committee of El Salvador and the Queen Margaret Research Ethics Panel approved the ethical aspects of this study. After handing participants' an information sheet describing the study and obtaining their consent to participate, interviews in Spanish (without interpreter) lasted between two to three hours and were audio-recorded. Their identities were duly anonymized to encourage free expression on a rather controversial topic in El Salvador. The field research was carried out over the course of two weeks, between June $13^{\text {th }}$ and June $27^{\text {th }}, 2018$. At the fieldwork's conclusion in the second study site (Usulután province), all participants, including farmers and health staff, were invited to take part in a wrap up meeting, which generated further group discussion on the preliminary results obtained and the way forward (Table 2).

\subsection{Data Analysis}

After transcribing audio-recorded interviews, and in line with the qualitative research paradigm, thematic data analysis was used to examine collected data on research participants' perspectives, identify similarities and differences in different participants' reports and summarize key themes. To ensure consistency and cohesion, data was handled in tandem with the Adaptation and Development after Persecution and Trauma (ADAPT) model [1].

\section{Findings}

\subsection{Safety/Security}

All participants in this study highlighted the long-standing existence of youth gangs controlling different community spaces in El Salvador as a major factor 
Table 2. Farmer primary information.

\begin{tabular}{ccccc}
\hline $\begin{array}{c}\text { Participant primary } \\
\text { information }\end{array}$ & Sex & Age & $\begin{array}{c}\text { Years worked in } \\
\text { agriculture }\end{array}$ & Health status \\
\hline Participant 1 & M & 78 & 68 & MeN-free \\
Participant 2 & M & 63 & 55 & MeN-controlled \\
Participant 3 & M & 72 & 60 & MeN-free \\
Participant 4 & M & 68 & 54 & MeN-free \\
Participant 5 & M & 62 & 52 & Men-controlled \\
Participant 6 & M & 60 & 52 & Men-controlled \\
Participant 7 & M & 55 & 45 & Men-controlled \\
Participant 8 & M & 55 & 43 & Men-controlled \\
Participant 9 & M & 37 & 30 & MeN-controlled \\
Participant 10 & M & 73 & 61 & Men-free \\
\hline
\end{tabular}

undermining broad social participation. The threat posed by gang activity is confirmed elsewhere. In a November 2018 report, the International Crisis Group reports that over the last three years, gang violence has killed nearly 20,000 people in El Salvador [20]. This figure situates the murder rate in this small country among the highest in the world. According to study participants, there are only few places in the country where gangs do not operate. The same report confirms that gangs are active in 94 per cent of 262 municipalities across the country and that these gangs exert considerable control over the daily lives of residents. Rather than putting up with all kinds of extortions, thousands prefer to travel northward along dangerous routes in search of greater safety. Those who stay back limit their movements.

Much of the violence, according to informants, is triggered by the illegal drug trade, as El Salvador lies along a major international south-to-north drug trafficking land route. An undated NARCONON report for El Salvador [21] informs that after the US, Mexican, and Colombian governments began to go after large drug cartels, they broke up into smaller cartels, which, in turn, began to offer Salvadorans a cut of the product to help them handle their shipments. According to informants, many of the country's youth, who have easy access to weapons, have also become addicted to crack cocaine (a cheaper version than pure cocaine) and amphetamine consumption as a result of this illegal activity. These developments cause many local residents to fear moving around in the public sphere. As one farmer stated:

"We actually don't feel our country is at peace."

They also complain that their government has channeled a significant portion of the country's financial resources into the war on drugs, thus leaving them with fewer resources to overcome poverty.

\subsection{Bonds/Networks}

Consulted stakeholders in this study reported that in many rural communities 
such as theirs, social violence and mass out-migration to urban centers and abroad, due to lack of local employment opportunities, has, inevitably, eroded established family and social networks. As one health promoter stated:

"Family breakdown plays a major role, especially because parents move on to the USA, leaving their children behind without support for socialization."

The social costs of family destructuration represent further barriers to community participation. Many surviving or left behind heads of household who only receive sporadic remittances from family members living abroad, if at all, have to struggle to ensure their families' livelihood and, therefore, have less time and energy to take part in social activities. They neither feel comfortable taking public transportation and showing up at social gatherings on their own. Their main contact with the community happens when they need to access available community services. Interviewed farmers also pointed out that another worrisome effect of declining bonds and networks is that many left behind children by migrating parents spend the remittances they receive carelessly, on drugs, alcohol, and guns, which contributes to a sense of community unsafety. There is, otherwise, little government investment to develop infrastructure that can help bring communities together, according to consulted stakeholders. As one farmer stated:

"Migration is inevitable because the government emerging from the conflict did nothing to foster integration. Many feel compelled to migrate for a better future."

\subsection{Justice}

Study participants shared a sense that, while government disinvestment in rural areas is evident, the activities of large agrochemical corporations are in continuous expansion. These stark differences in economic outcomes between different sectors in society have generated a collective sense of injustice within rural communities, due to the perception of an existing collusion between government and large corporation interests. From this perspective, many residents in farming communities have learned to not expect much by way of community support for their wellbeing. Even though the government at the time of this study has undertaken major health system reform to improve health prevention, health catchment areas remain far too large for the small size of health promotion teams. In practice, this means that health outreach efforts concentrate primarily on mother and child health, which constitutes the bulk of the local health demand. It is, therefore, difficult to conduct community awareness raising and health screening campaigns focused on $\mathrm{MeN}$, in coordination with the NHF, and ensure necessary follow up of $\mathrm{MeN}$ cases in the community, as it is a far longer term and less visible issue than other health problems. As one health promoter stated:

"I m supposed to cover 200 families in my care unit but, in fact, I follow 400"

These health system shortcomings reinforce farmers' perceptions that $\mathrm{MeN}$ is 
not considered a health priority. Instead, they are more frequently visited by agronomists linked to the agrochemical industry who promote use of their chemical products. All consulted farmers were aware that many of these products have been banned in the countries that manufactured them, due to their pernicious effects on health and the environment. A prime example is Gramoxone (Paraquat), the most extensively used herbicide in El Salvador, which has been banned in 38 other countries [22]. They were also aware of existing legislation in regard to occupational safety measures in agricultural sector, but consistently reported that these were not enforced in practice. Furthermore, they felt that informed professionals, like medical doctors, did not use their influential position to denounce these bad practices in public. These combined perceptions only confirmed their sense of institutional abandonment and strengthened their sense of injustice. As one farmer pointed out:

"If we don't invest in prevention here, we die, because it's too expensive to receive adequate treatment."

\subsection{The National Healthcare System-National Health Forum Partnership}

After winning the 2009 elections in El Salvador, the FMLN party launched a major health reform, which led to the establishment of the Integrated and Integral Health Networks and the National Health Forum in 2010 as two mechanisms to ensure its roll out [2]. One of the main goals of this reform, which takes its reference from the primary health care paradigm, as defined in the Alma Ata Declaration, is to create spaces for community participation. Since then, both the IIHN and NHF have gained an important territorial presence throughout the country, with the objective of improving access to health services and encouraging broader community participation to guarantee the right to health.

With respect to the MeN epidemic, the NHS-linked IIHN has established a coordination mechanism with hospital and health center-based health promoters to develop multidisciplinary teams, including educators and psychologists, to provide holistic care to MeN patients. The NHF has created a thematic working group, which, in its advisory capacity, has visited agricultural cooperatives to raise awareness of potential risk factors for chronic kidney disease. During these visits, NHF representatives also identify farmers' health needs and then include them in the public health policy agenda for discussion during meetings with NHS representatives. The NHF has also organized participatory discussion tables and made health prevention announcements regarding MeN through television and radio. The interviewed WG representative had been a farmer himself, and, therefore, was very sensitive to the MeN epidemic. However, among the remaining interviewed farmers, none of them held a close relationship with either the IIHN or NHF, although they were aware of their existence.

Throughout their $30+$ years laboring in agriculture, all interviewed farmers had become fully aware of the health threat posed by the use of highly toxic pesticides in their work environment, not least because they had all suffered intoxi- 
cations by pesticide exposure at one point in their lives and seen younger colleagues die from damaged kidneys. As one farmer stated:

"I was fumigating and started to see the trees as if they were going around in circles. Since then, I can no longer apply pesticides. As soon as I thought about re-using the poisons, I started to feel bad. I woke up to the risk."

This awareness had led a portion of respondents to develop homegrown protective strategies to counter this threat, which had kept them disease-free. Remaining participants, who had contracted MeN but managed to control its progression under medical supervision, had adopted similar strategies. They are summarized in Table 3.

Furthermore, all informants felt that the national authority responsible for agriculture could undertake a set of protective measures to enhance farmer safety, as detailed in Table 4 .

Interviewed farmers were not associated to any of the health prevention activities launched by the IIHS-NHF partnership in regard to the MeN epidemic. Their fund of knowledge and skill to prevent MeN was, therefore, being lost on the wider exposed farmer population. This finding raises the question as to how different concerned stakeholders, including the IIHS, (represented by the nephrology teams based at the local health centers) the NHF and MeN-resilient farmers can work closer together to boost community-wide $\mathrm{MeN}$ prevention?

\section{Discussion}

The MeN epidemic in El Salvador is occurring in a post-conflict environment that is still fraught with multiple adversities for poor farmers and their families living in economically and socially marginalized rural communities. Although the IIHS-NHF health promotion partnership lays emphasis on community

Table 3. Farmer self-generated strategies.

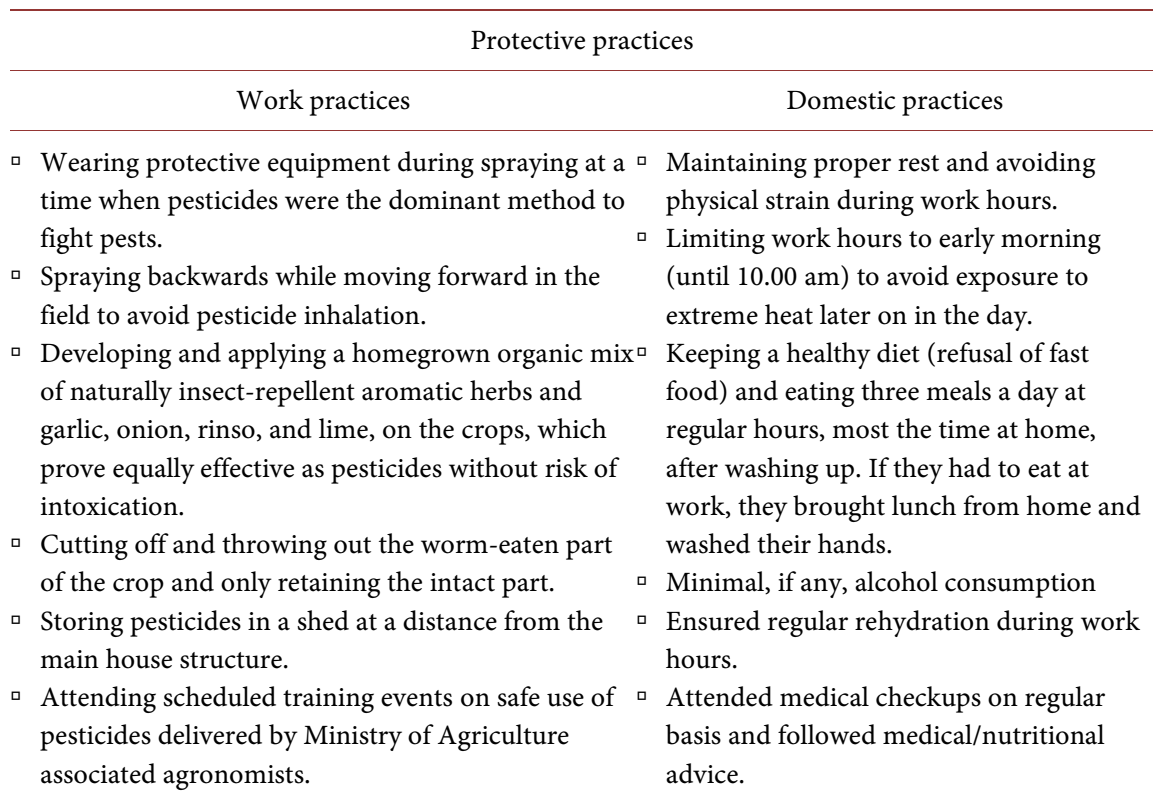


Table 4. Farmer safety.

\begin{tabular}{|c|c|c|}
\hline \multicolumn{3}{|c|}{ Safety recommendations } \\
\hline & $\begin{array}{l}\text { Recommended safety measures at } \\
\text { governmental policy level }\end{array}$ & $\begin{array}{l}\text { Recommended safety measures } \\
\text { at field level }\end{array}$ \\
\hline & $\begin{array}{l}\text { Banning pesticides that have been banned } \\
\text { elsewhere in the world. } \\
\text { Strengthen local health systems' ability to } \\
\text { conduct more frequent and wider health } \\
\text { screening campaigns for early detection of } \\
\text { MeN. } \\
\text { Fund large-scale environmental studies to } \\
\text { determine level of water contamination in } \\
\text { certain rural areas and introduce } \\
\text { environmental protection measures based on } \\
\text { collected evidence. }\end{array}$ & $\begin{array}{l}\text { Ensure appropriate pesticide disposal } \\
\text { mechanisms to prevent environmental } \\
\text { contamination. } \\
\text { - Facilitate transition to organic farming methods. } \\
\text { daily work limits, use of protective equipment } \\
\text { during pesticide spraying periods and permitting } \\
\text { rehydration pauses. } \\
\text { rehydration purposes, as clinical pictures } \\
\text { consistently reveal electrolytic disturbances. }\end{array}$ \\
\hline
\end{tabular}

participation in health initiatives, this study found that sampled farmers' links with $\mathrm{MeN}$ prevention efforts remain weak, given their enduring instability. When applied to the MeN epidemic in El Salvador, the fact that community participation for health remains limited in the most affected areas means that state-led MeN prevention efforts are not able to draw upon the popular knowledge held by MeN-resilient farmers, such as those interviewed for this study, to enhance prevention efforts. In this framework, many farmers only hear about protective measures once they reach the health system at stage 4 or 5 of kidney disease, when many have to go directly on hemodialysis. By that point, many find it extremely hard to follow treatment, either because public dialysis facilities are too distant, overcrowded, or because of stigma attached to this disease, and private treatment is far too expensive for most. Many remain at home and let themselves die.

Farmer involvement in MeN prevention efforts is, therefore, crucial to extend $\mathrm{MeN}$ prevention in affected communities but this study shows that increased institutional support to stabilize disrupted psychosocial pillars in their lives is essential to leverage farmer participation. There would surely be many more farmers than those interviewed in this study that could play a valuable role in wider $\mathrm{MeN}$ prevention efforts if the health system partnership helped create the social conditions that are required to elicit their regular participation. As the director of the Fondo Social de Emergencia para la Salud (a community registry of Chronic Kidney Disease in the Bajo Lempa region of El Salvador in Canton Tierra Blanca, Usulután) stated during the interview:

"It's $[\ldots M e N]$ essentially a problem of mental health, as many struggling farmers give scarce attention to their health even after being diagnosed."

A similar situation is happening elsewhere in the world where MeN continues to be a major public health concern. While searching for the exact cause of MeN, worldwide morbidity rates for this preventable disease are not showing signs of decline. This unchanging disease pattern highlights the need for a parallel investment to support national health systems to dedicate further resources to 
$\mathrm{MeN}$ prevention. Since community participation is an essential component of any health prevention strategy in impoverished communities, national health systems need further support to assess and remove existing barriers to broader farmer participation. This study shows that poor farmers in contexts with a history of violent conflict continue to face a set of psychosocial challenges that can have a destructive effect on their motivation to participate in health prevention efforts. National health systems, therefore, need to create mechanisms that help farmers stabilize these challenges. This strategy is otherwise essential to gain the popular impetus that is required to promote health prevention strategies at other levels, like the ongoing effort to pass legislation on banning highly toxic agrochemical products to improve the quality of food, water, and air farmers are exposed to, or reform occupational health risk legislation.

\section{Conclusions and Recommendations}

In light of these research findings, it appears necessary for the IIHS-NHF partnership to scale up its health-promoting role by creating further opportunities for community gatherings during which, by applying a health education model, partners can facilitate discussions on shared social vulnerabilities that may constrain wider community participation in health initiatives. With increased information about these crucially important psychosocial aspects and a sense of shared concerns, community groups can then generate joint initiatives to stabilize disrupted pillars in their lives, involving both the IIHS and NHF, for necessary support.

While this measure may be the first step towards increasing farmer participation in health-enhancing initiatives, the IIHS-NHF partnership can also integrate resilient farmers, such as those that were interviewed during this study, in $\mathrm{MeN}$ awareness raising work at rural health centers and in other community spaces so that they can share their acquired knowledge and skills regarding MeN prevention and serve as role models for other farmers. At a final wrap-up meeting involving all interviewed stakeholders in this study, the group agreed that this approach is vital to strengthen community-health system cooperation for MeN prevention. Further exchange of experiences in community-health system cooperation that can be usefully applied to tackle widespread epidemics like $\mathrm{MeN}$ is necessary to enhance the MeN prevention response worldwide.

\section{Acknowledgements}

K.B. thanks the MINSAL and NHF lead staff who facilitated this research in El Salvador, as well as health center-based nephrologists, health promoters and farmers who volunteered their time and knowledge to inform the research questions.

\section{Conflicts of Interest}

The authors declare no conflicts of interest regarding the publication of this paper. 


\section{References}

[1] Silove, D. (2013) The ADAPT Model: A Conceptual Framework for Mental Health and Psychosocial Programming in Post Conflict Settings. Intervention, 11, 237-248. https://doi.org/10.1097/WTF.0000000000000005

[2] Ministerio de Salud de El Salvador (2009) Construyendo la esperanza Estrategias y Recomendaciones en Salud.

http://www.salud.gob.sv/servicios/descargas/documentos/Documentaci\%25C3\%25

B3n-Institucional/Pol\%25C3\%25ADtica-Nacional-de-Salud/Pol\%25C3\%25ADticade-Salud---Construyendo-la-Esperanza

[3] Orantes-Navarro, C.M. (2017) Enfermedad renal crónica en el El Salvador: Una doble epidemia. Nefritis Intersticial Crónica de las Comunidades Agrícolas (NICCA). Ministerio de Salud, Viceministerio de Servicios de Salud, Dirección Nacional de Enfermedades No Transmisibles.

[4] Ordunez, P., et al. (2017) Chronic Kidney Disease Mortality Trends in Selected Central America Countries 1997-2013: Clues to an Epidemic of Chronic Interstitial Nephritis of Agricultural Communities. Journal of Epidemiology \& Community Health, 72, 280-286. https://doi.org/10.1136/jech-2017-210023

[5] Ramirez-Rubio, O., McCLean, M.D., Amador, J.J. and Brooks, D.R. (2013) An Epidemic of Chronic Kidney Disease in Central America: An Overview. Postgraduate Medical Journal, 89, 123-125. https://doi.org/10.1136/postgradmedj-2012-201141rep

[6] Carranza, G.C., Huaman de Aguirre, E. and Lovo Cordova, J.A. (2011) Factores de riesgo de la insuficiencia renal crónica. Unidad Médica Instituto Salvadoreño de Seguro Social, San Miguel, El Salvador.

[7] Orantes-Navarro, C.M., Orellana, P. and Vela Parada, X.F. (2015) Epidemiological Characteristics of Chronic Kidney Disease of Non-Traditional Causes in Women of Agricultural Communities of El Salvador. Clinical Nephrology, 83, 24-31. https://doi.org/10.5414/CNP83S024

[8] Wesseling, C. and Weiss, I. (2017) Enfermedad renal crónica de etiología desconocida o de origen no tradicional: Una epidemia global? Archivo de Prevención de Riesgos Laborales, 20, 200-202. https://doi.org/10.12961/aprl.2017.20.04.1

[9] Herath, C., et al. (2017) Kidney Diseases in Agricultural Communities: A Case against Heat-Stress Nephropathy. Kidney International Reports, 3, 271-280. https://doi.org/10.1016/j.ekir.2017.10.006

[10] González Oliva, X. (2018) Dos salvadoreños mueren al día por enfermedad renal. El Diario de Hoy. El Periódico de El Salvador.

[11] Ramirez, M. (2013) Nefrólogos no apoyan tesis de tóxicos y mal renal. El Diario de Hoy. El Periódico de E Salvador.

[12] PAHO/WHO (2013) Kidney Disease of Unknown Causes in Agricultural Communities in Central America Is Declared a Serious Public Health Problem.

[13] Ferrer, A. (2003) Pesticide Poisoning. Anales Sis San Navarra, 26, 155-171. https://doi.org/10.4321/S1137-66272003000200009

[14] Garcia-Trabanino, R., et al. (2015) Heat Stress, Dehydration, and Kidney Function in Sugarcane Cutters in El Salvador-A Cross Shift Study of Workers at Risk of Mesoamerican Nephropathy. Environmental Research, 142, 746-755. https://doi.org/10.1016/j.envres.2015.07.007 http://www.elsevier.com/locate/envres

[15] Roncal-Jimenez, C., Lanaspa, M.A., Jensen, T., Sanchez-Lozada, L.G. and Johnson, 
R.J. (2015) Mechanisms by Which Dehydration May Lead to Chronic Kidney Disease. Annals of Nutrition \& Metabolism, 66, 10-13.

https://doi.org/10.1159/000381239

[16] Mejía, R., et al. (2014) Pesticide-Handling Practices in Agriculture in El Salvador: An Example from 42 Patient Farmers with Chronic Kidney Disease in the Bajo Lempa Region. Occupational Diseases and Environmental Medicine, 2, 56-70. https://doi.org/10.4236/odem.2014.23007

[17] Valcke, M., Levasseur, M.-E., Soares da Silva, A. and Wesseling, C. (2017) Pesticide Exposures and Chronic Kidney Disease of Unknown Etiology: An Epidemiologic Review. Environmental Health, 16, 49. https://doi.org/10.1186/s12940-017-0254-0

[18] Silva, L.C. and Ordunez, P. (2014) La enfermedad renal crónica en las comunidades agrícolas de América Central: Desafíos para la epidemiología y la salud pública. MEDICC Review, 16, 66-71.

[19] United States Institute of Peace (1993) From Madness to Hope: The 12-Year War in El Salvador. Report of the Commission on the Truth for El Salvador.

[20] International Crisis Group (2018) Life under Gang Rule.

[21] NARCONON (Undated) El Salvador Cocaine and Drug Addiction Problem. https://www.narconon.org/drug-information/el-salvador-cocaine-drugs.html

[22] Watts, M. (2017) Consolidated List of Bans. PANAP on Behalf of PAN International. 